\title{
简议幼儿音乐游戏教学的意义及其措施
}

\author{
王阳 \\ 赤峰市红山区第五幼儿园 \\ DOI:10.32629/er.v2i3.1726
}

[摘 要] 音乐教育是学前教育课程体系中的重要内容, 德国的奥尔夫、瑞士的达尔克罗兹等儿童音乐教育理论都是以游戏方 式为基础,对儿童进行音乐素质的培养。游戏是幼儿的基本活动,也是他们和周围世界互动、学习的基本方式,在游戏中孩子们 处于积极主动的状态,对其运动器官的发展以及个性品质的形成具有重要意义。基于此,本文阐述了幼儿音乐游戏教学存在的 主要问题, 对幼儿音乐游戏教学的重要意义及其措施进行了论述分析。

[关键词] 幼儿音乐游戏教学; 问题; 意义; 措施

幼儿音乐教育目的是挖掘和发展启蒙期幼儿潜在的音 乐素质和表达能力, 继而在内容丰富、形式多样的音乐游戏 实践活动中, 即在唱一唱、跳一跳、玩一玩、乐一乐的过程 中, 让幼儿去感知和体验音乐的鬼力, 从而获得相应的音乐 知识和表演技能, 即能唱、会跳、能欣赏、会创造, 在客观接 受和主动创造的音乐游戏活动中表现音乐, 萌发幼儿去认识 美、感觉美和表现美。《幼儿教育纲要》艺术教育指出要使 幼儿 “初步感受并喜爱环境、生活和艺术中的美” , “幼儿 园应为幼儿提供健康、丰富的生活和活动环境, 满足他们多 方面发展的需要, 使他们在快乐的童年生活中获得有益于身 心发展的经验。” 的教育目的。所以幼儿音乐课程教育, 是整 个幼儿教育活动中不可或缺的重要内容之一, 其是通过音乐 的形象思维来启发、引导和激发幼儿的智力开发, 并且必须 是以引导幼儿参与唱歌、音乐律动、音乐游戏、舞蹈等音乐 实践活动为基本教育内容, 以期在教育实践活动中对幼儿进 行美育教育。

\section{1 幼儿音乐游戏教学存在的主要问题分析}

幼儿音乐教育应以游戏般的快乐心情开始, 再以游戏般 的快乐心情引导到正确的方向, 让孩子们在音乐活动中健康 愉快的成长。教师只有不断的用更深入的视角反思, 用不同 的策略与方法, 科学的将游戏精神融入音乐教育活动之中才 能让孩子们终生受益。

但是笔者在幼儿音乐游戏实践教学过程中发现, 始终存 在着不同程度的形式化与低效化等问题。主要存在关注游戏 的外在形式忽视游戏的基本精神; 注重教师自身的教育意图 忽视幼儿的需求与能力差异; 注重游戏的情境性忽视挑战性 与创新性等等。笔者认为导致上述问题存在的主要原因是教 学目标的制定简单、教学内容的选择单调、互动形式的手法 单一。因此教师们只有明确游戏的核心特性, 尊重儿童的文 化需求与个体差异, 选择多元化的音乐活动内容, 将游戏与 音乐有机融合, 不断提升教育机智与教学个性, 才能增强音 乐教育游戏化的有效性与适宜性。

\section{2 幼儿音乐游戏教学的重要意义}

幼儿园工作程序明确了 “遵循幼儿身心发展的规则符合
幼儿的年龄特征” 作为幼儿园教育的原则之一, 首先, 在内容 的选择上必须符合幼儿的年龄特征。幼儿喜欢动物, 模仿力 强, 对音乐节奏也有初步的了解, 而小鼠类的机智、幽默、动 物形象更受欢迎幼儿的喜爱; 除了音乐节律性活动, 孩子们 选择音乐节奏尤为重要, 比如《小老鼠和泡泡糖》, 这段音乐 简单容易理解, 通过模仿小老鼠、泡泡糖和其他运动, 你可以 让孩子们感到无限乐趣的音乐活动。音乐游戏在一定的规则 和指导下, 在特定地点、规则的指导下由学生们逐渐接受训 练来观察自律的自我意识。在音乐教学中, 集体游戏的使用 可以最大限度地提高学生的自我意识和自律行为, 使纪律严 明的学生养成遵守纪律的习惯。其意义主要表现为: (1) 幼 儿音乐游戏教学充分体现了快乐教学。游戏, 是一种能够带 来刺激和愉悦的活动。而幼儿正处于活泼爱玩的年纪, 适合 幼儿的游戏更会让他们感到快乐。音乐游戏, 在教学中将游 戏和音乐融合到一起, 这符合幼儿的身心特点, 可以创建一 种轻松愉悦, 自由活力的氛围, 帮助幼儿在玩要中学到音乐 知识, 在学习中获得玩要的快乐, 体会到音乐的魅力。(2) 提 高幼儿的全面素质。音乐游戏灵活多变, 将音乐游戏化, 让幼 儿在多种形式的游戏中接受音乐教育, 不仅可以激发幼儿的 对音乐的接受能力, 提高幼儿对音乐知识的学习兴趣和掌握 能力, 还可以让幼儿在音乐伴奏下的游戏中, 提高音乐审美 能力、想象能力、探索能力和遵循游戏规则等诸多方面, 可 谓全面提升幼儿的素质。

\section{3 加强幼儿音乐游戏教学的措施}

3.1 做好幼儿音乐游戏的设计

选择适合幼儿的音乐材料。音乐游戏的种类选择多种多 样, 在开展前要根据幼儿发展的身心特点和实际情况进行篮 选, 选择贴近幼儿生活, 让幼儿便于理解的内容, 更能够调动 幼儿的参与积极性。选择趣味性强的音乐。音乐游戏是以游 戏的方式进行的, 因此在音乐的选择上就要有趣味性, 节奏 欢快, 有高潮, 这样更能满足幼儿的心理需求, 激发幼儿的游 戏热情。设计适合幼儿的动作。音乐游戏是一种互动性、配 合性的活动, 幼儿音乐教师在设计音乐游戏时就要充分考虑 幼儿的身体发育情况、参与的人数、学习动作的能力等实际 
问题, 根据不同年龄段的幼儿设计适合不同年龄段幼儿的动 作, 这些动作简单易学, 灵活有趣, 才更容易让幼儿在参与游 戏中保持学习的热情。设计简单有趣的游戏过程。幼儿的理 解能力和学习能力有限, 音乐游戏的设计必然不能太过复杂, 太过复杂的游戏会使得幼儿丧失学习的积极性。而事实上, 越是简单的游戏越能明确地表现出音乐的主题, 在保证游戏 乐趣的基础上, 幼儿对简单的游戏更能记忆深刻。

3.2 幼儿音乐游戏教学需要尊重幼儿的个体差异需求

幼儿音乐游戏教学过程中, 必须顺应幼儿的特点与需要, 把游戏、音乐、情境等作为一个有机的整体, 引导幼儿对音 乐进行整体性的感知与个性化的表现。如“一条小鱼游来了” 是小班孩子们的 “最爱”, 每次进行表演他们都乐此不疲, 孩子在游戏中喜欢夸张自己的动作, 有节奏地四处穿行, 表 情动作生动可爱, 由此孩子的情绪得到了最大愉悦。《3-6 岁 儿童学习与发展指南》中指出要始终遵循幼儿的发展规律和 学习特点。珍视幼儿生活和游戏的独特价值, 充分尊重和保 护其好奇心和学习兴趣, 创设丰富的教育环境, 合理安排一 日生活, 最大限度地支持和满足幼儿通过直接感知、实际操 作和亲身体验获取经验的需要; 尊重幼儿发展的个体差异。 既要准确把握幼儿发展的阶段性特征, 又要充分尊重幼儿发 展连续性进程上的个别差异, 支持和引导每个幼儿从原有水 平向更高水平发展的原则。幼儿有着自己的文化, 有着自己 的逻辑、规则与独特的文化需求。游戏, 作为儿童生活和儿 童文化的一个自然而重要组成部分, 它实际上是儿童存在的 一种形式, 是幼儿生存的一种状态。

3.3 开展过程中保证音乐游戏的游戏性

虽然音乐游戏是音乐教学的方法, 很多教师也会为了完 成教学目标而开展游戏, 但这种音乐游戏却是不可取的。音 乐游戏的独特性就在于它的游戏性, 让幼儿在自由快乐的游 戏过程中不知不觉地学会音乐知识, 体会到音乐的鬼米力、游 戏的快乐, 这才是音乐游戏的真正需要走的途径。因此, 想要 有效地带领组织幼儿开展音乐游戏, 保持音乐游戏的游戏性 是关键。开展过程中保持音乐游戏的游戏性可以从以下两方 面做起, 一方面幼儿音乐教师要放下架子, 和幼儿平等沟通, 融入到它们中去, 和幼儿成为游戏中的伙伴, 共同推进游戏
的进程, 而不是高高再生用教师的口吻发号施令, 这是不符 合音乐游戏原则的; 另一方面, 要充分发挥幼儿的能动性, 音乐游戏中幼儿才是游戏的主体, 而且幼儿单纯的天性和天 马行空的想象力, 教师在游戏中要鼓励幼儿发挥自己的天性, 开展丰富的想象, 畅所欲言, 这会给音乐游戏注入更多的活 力和可能性, 也更能调动幼儿的参与积极性, 让音乐游戏收 到更好的效果。

\section{4 不断提升教师的综合素质}

组织音乐游戏化的活动需要教师运用多元的教学智慧, 为孩子创设开放、自由、宽松的游戏环境, 提供更多的自主 自由选择与表达的权利与机会, 及时发现幼儿富有创造性与 个性的音乐表现方式, 适时适当的予以赏识与鼓励。适宜与 有效的游戏化教学活动需要富有游戏性的教师。利伯曼关于 教师所应具有的个性特征的研究表明, 教师应具有幽默感、 快乐和笑声、热情、积极参与、灵活、想象等八种良好的个 性特征, 其中有半数以上与游戏性有关。幼儿教师应进一步 提升自己的热情、幽默、风趣等良好个性, 为游戏化音乐活 动注入更多的笑声与乐趣, 从而感染与打动孩子。

\section{4 结束语}

综上所述, 游戏做为幼儿音乐教学活动的基本形式, 其 融入幼儿园音乐教学中, 让孩子们在游戏中体验音乐气息、 获得音乐知识; 在学习中体验游戏过程的快乐, 从而促进幼 儿在智力、身体、个性、情感、社会性等全面发展。

\section{[参考文献]}

[1]徐春兰.浅析幼儿音乐游戏教育存在的问题 [J].课程 教育研究,2017(12):25-26.

[2]吴建维.浅析幼儿音乐游戏的开展策略 [J]. 北方音 乐,2015(14):36.

[3]朱亚佩.幼儿音乐活动游戏化的实践效果分析 [J].中 国校外教育,2016(05):42.

[4]陈瑶瑶.如何在幼儿音乐教学中有效运用音乐游戏 [J].新教育时代,2017(06):51。

[5]王荣.如何在幼儿音乐教学中有效运用音乐游戏 [J]. 黄河之声,2017(23):12-13. 